\title{
Refractory Cardiogenic Shock
}

\author{
Bhupinder Natt, MD (bnatt@deptofmed.arizona.edu) \\ Tauseef Afaq Siddiqi, MD (tsiddiqi@deptofmed.arizona.edu) \\ Jarrod Mosier, MD (jmosier@aemrc.arizona.edu) \\ Yuval Raz, MD (yraz@deptofmed.arizona.edu)
}

Department of Medicine, Division of Pulmonary, Allergy, Critical Care and Sleep

Medicine, University of Arizona, Tucson, AZ

\begin{abstract}
We present a case of refractory cardiogenic shock secondary to myxedema crises that was treated successfully with thyroid hormone replacement.
\end{abstract}

\section{Case Presentation}

History of Present IIIness

A 62-year-old woman with past medical history significant only for hypothyroidism was seen in the emergency department (ED) after a fall at home. On further evaluation, the patient's husband reported history consistent with deteriorating mental function as evident by speech alteration, inability to operate home appliances like the coffeemaker and gradually worsening generalized weakness. She was recently seen at an outside hospital the week previous to this admission and given a prescription for furosemide for pedal edema.

ED evaluation showed her to be lethargic, disoriented with progressively deteriorating mentation, with hypothermia and bradycardia. Her progressive decline in mentation led to endotracheal intubation for airway protection. The patient was started on vasopressors due to post-intubation hypotension and transferred to the Medical Intensive Care Unit (MICU).

Vitals and Physical Exam

Vitals upon presentation to ED: Temperature $29^{\circ}$ Celsius; Heart Rate $42 \mathrm{bpm}$; Blood Pressuren107/79 mm Hg; Respiratory Rate 14/min; SpO2 97 \% on Room Air. Vitals upon arrival in MICU: Temperature of $29^{\circ}$ Celsius; Heart Rate $43 \mathrm{bpm}$; Blood Pressure 111/57 mmHg; Respiratory Rate of 10/min; SpO2 100\% on mechanical ventilation;

Neurologically, she was sedated with no obvious localizing signs. Skin exam revealed a sutured scalp lesion and scattered abrasion on arms. Cardiopulmonary exam was significant only for bradycardia, which was determined to be sinus rhythm by the electrocardiogram (EKG). Other system examination was significant only for 2+ nonpitting edema of upper and lower extremities. 


\section{Laboratory and Radiology Data}

CBC: White Cell Count 8.4×1000/microL; Hemoglobin 9.5 g/dL; MCV 100 fL; Platelets $82 \times 1000 /$ microL.

Electrolytes and Metabolic Panel: Sodium $134 \mathrm{mMol} / \mathrm{L} ;$ Potassium $4.2 \mathrm{mMol} / \mathrm{L} ;$ Chloride $97 \mathrm{mMol} / \mathrm{L}$; Bicarbonate $26 \mathrm{mMol} / \mathrm{L}$; Urea Nitrogen $38 \mathrm{mg} / \mathrm{dL}$; Creatinine $0.9 \mathrm{mg} / \mathrm{dL}$. Glucose $78 \mathrm{mg} / \mathrm{dL}$; Calcium $9.6 \mathrm{mg} / \mathrm{dL}$.

Total Protein 6.3 g/dL; Albumin $3.7 \mathrm{~g} / \mathrm{dL}$; Bilirubin $0.7 \mathrm{mg} / \mathrm{dL}$; Alkaline Phosphate 104 IU/L; ALT 72 IU/L; AST 158 IU/L; TSH 36.1 ulU/mL; Thyroxine 0.8 ng/dL; Free T3 1.2 $\mathrm{pg} / \mathrm{mL}$ (Normal 2.4-4.2 $\mathrm{pg} / \mathrm{mL}$ ); Cortisol $20.3 \mathrm{mcg} / \mathrm{dL}$.

ABG: pH 7.52; $\mathrm{PaCO} 2$ 34; $\mathrm{PaO} 2$ 166; $\mathrm{HCO} 328 ; \mathrm{SaO} 297.6 \%$ on 50\% $\mathrm{FiO} 2$.

Urine Analysis: Negative.

Urine Drug Screen: Negative.

Chest X-Ray: Emphysematous changes with no acute cardiopulmonary process. Non-contrast CT of the head and cervical spine: Unremarkable except scalp hematoma.

\section{EKG at Presentation}

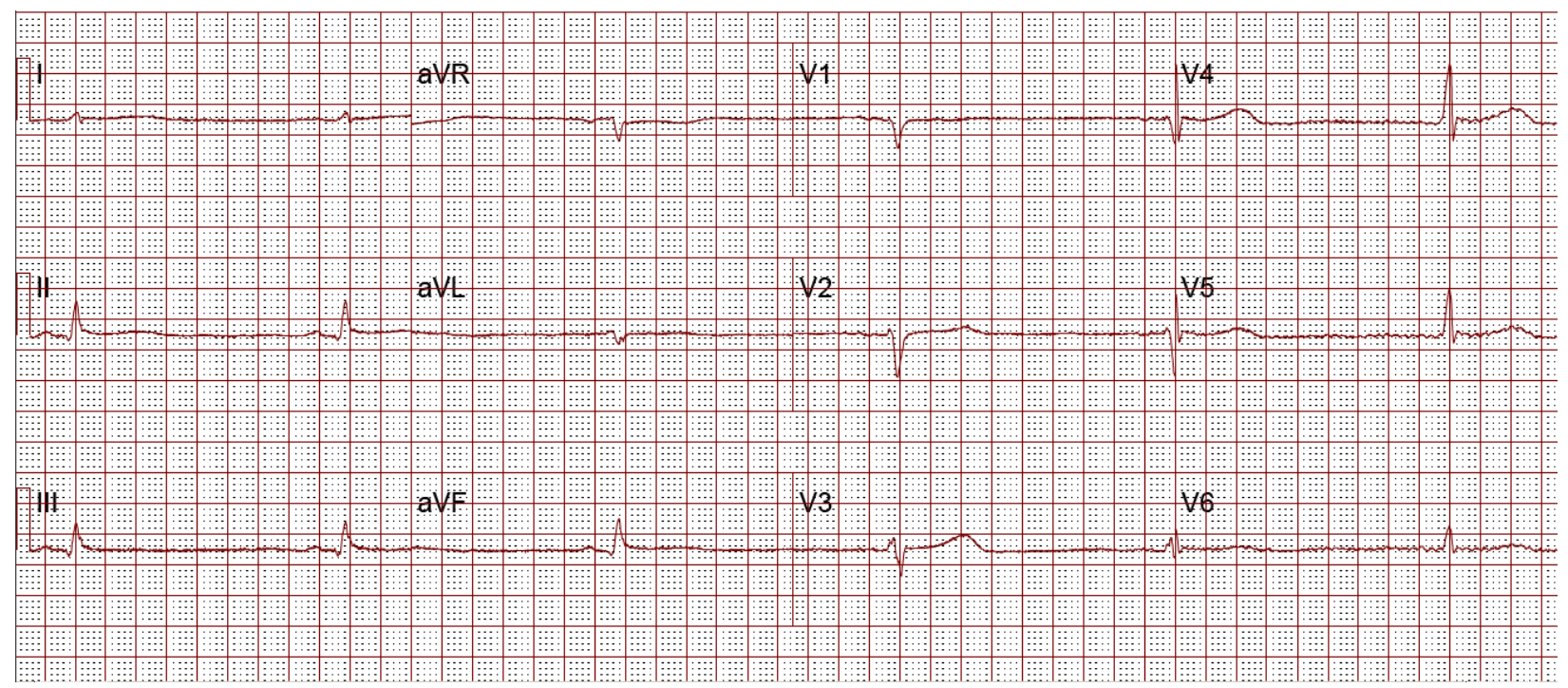

\section{MICU Course}

After initial stabilization of blood pressure in ED; receiving four liters of intravenous fluids; and norepinephrine infusion at increasing doses, she was transferred to MICU. She required two more liters of crystalloids, vasopressin and increasing doses of norepinephrine, epinephrine, phenylephrine and dobutamine infusions. Corticosteroid was added for refractory shock. She also received first dose of broad-spectrum antimicrobials in ED. 
Two hours after arrival to the MICU, seven hours post presentation to the ED; a SwanGanz pulmonary artery catheter was placed. The values obtained from the Swan-Ganz catheter are reported in table 1.

Table 1. Initial pulmonary artery catheter values after admission to the MICU.

\begin{tabular}{|l|l|}
\hline Parameter & Values \\
\hline Temperature (degree Celsius) & 32.2 \\
\hline Heart Rate (beats per minute) & 52 \\
\hline Arterial Blood Pressure (mmHg) & Systolic 63. Diastolic 42. Mean 50 \\
\hline Pulmonary Artery Pressure (mm Hg) & Systolic 19. Diastolic 15. Mean 15 \\
\hline Cardiac Index (L/min/m2) & 2.8 \\
\hline SVR (dynes-sec/cm5) & 1600 \\
\hline PCWP (mm Hg) & 14 \\
\hline SvO2 & 79 \\
\hline
\end{tabular}

These values were obtained seven hours into admission, while the patient was being actively rewarmed, treated with a total of six liters (L) of crystalloid solutions and on norepinephrine at $13 \mathrm{mcg} / \mathrm{min}$ and dobutamine at $5 \mathrm{mcg} / \mathrm{kg} / \mathrm{min}$.

The patient remained hypotensive and sequentially, within hours, multiple vasopressors and inotropic agents were required. Table 2 reports the vitals and values off the SwanGanz catheter 12 hours after initial placement, when the patient is being actively rewarmed, treated for close to 18 hours and while receiving intravenous epinephrine at $3 \mathrm{mcg} / \mathrm{min}$, norepinephrine at $30 \mathrm{mcg} / \mathrm{min}$, vasopressin a $0.03 \mathrm{units} / \mathrm{min}$, phenylephrine at $150 \mathrm{mcg} / \mathrm{min}$ and dobutamine at $20 \mathrm{mcg} / \mathrm{min}$.

Table 2. Pulmonary artery catheter values 12 hours after admission to the MICU.

\begin{tabular}{|l|l|}
\hline Parameter & Values \\
\hline Temperature (degree Celsius) & 33.7 \\
\hline Heart Rate (beats per minute) & 56 \\
\hline Arterial Blood Pressure $(\mathrm{mmHg})$ & Systolic 86. Diastolic 51. Mean 63 \\
\hline Pulmonary Artery Pressure $(\mathrm{mm} \mathrm{Hg})$ & Systolic 26. Diastolic 15. Mean 19 \\
\hline Cardiac Index (L/min/m2) & 3 \\
\hline SVR (dynes-sec/m5) & 928 \\
\hline PCWP (mm Hg) & 11 \\
\hline SvO2 & 75 \\
\hline
\end{tabular}

A formal 2-D echocardiogram was obtained which showed a global left ventricular dysfunction and hypokinesis with reduced ejection fraction of $35 \%$ and mildly reduced right ventricular dysfunction. No major valvular or pericardial pathology was noticed. Given the patient's history and clinical features of hypothyroidism, a diagnosis of myxedema coma was made and treatment started with levothyroxine $125 \mathrm{mcg}$ a day intravenously. Corticosteroids were discontinued due to concern of blockage of peripheral conversion of T4 to T3. T3 was unavailable in our city initially but was subsequently obtained and prescribed to our patient at $25 \mathrm{mcg}$ of liothyronine three 
times a day. She responded very well to the treatment and was successfully weaned off all vasopressor support, liberated from mechanical ventilation on the fourth day and transferred out of the MICU on day five of admission. Limited repeat echocardiogram prior to transfer out of the MICU showed an ejection fraction of $65 \%$.

Cultures, lumbar puncture and all imaging including brain MRI obtained during admission and MICU stay remained negative. A potential precipitating factor was not found and all empiric treatments were gradually withdrawn prior to the transfer out of MICU.

Retrospective history taking revealed patients' non-compliance with levothyroxine treatment for the past 2 years. She had been given a dose of levothyroxine while she was admitted at the outside hospital the week previously leading to her relatively normal T4 level, suggesting inhibited peripheral conversion to T3 and thus the limited effect of intravenous levothyroxine initially. Surprisingly, despite the ordeal, she continued to refuse to take the medication once extubated and transferred to Medicine.

\section{Discussion}

A myxedema crisis is an extreme and life-threatening form of hypothyroidism that requires prompt diagnosis and treatment. Mortality rate has been reported as high as $60 \%$ despite appropriate diagnosis and management $(1,2)$. Infections and discontinuation of thyroid supplements are the major precipitating factors. Other precipitants include hypothermia, gastrointestinal bleeding, congestive heart failure, cerebrovascular accident, metabolic disturbance and sedative drugs (3).

Myxedema crises manifests by involving multiple organ systems. Hypothermia can be profound and is usually the first sign of myxedema coma. Neuropsychiatric manifestations include confusion, lethargy, coma, psychosis (myxedema madness), and seizures. Respiratory depression is common likely due to depressed hypoxic and hypercapnic respiratory drive. Edema (myxedema) involving upper airways contributes to acute respiratory failure. Reduced intestinal motility leads to constipation, paralytic ileus and mega colon. Urine retention from bladder atony can be seen. Reduced glomerular filtration and reduced water excretion leads to hyponatremia, a consistent finding in myxedema crises.

Cardiovascular effects of myxedema crises include conduction abnormalities, reduced contractility, cardiomegaly and pericardial effusion. Sinus bradycardia, low voltage complexes, bundle branch blocks, complete heart blocks, and nonspecific ST-T changes in electrocardiogram have been reported. Prolonged QT interval and polymorphic ventricular tachycardia has been described as well (4). Depressed cardiac contractility leads to low stroke volume and cardiac output. Animal studies have documented that hypothyroidism leads to cardiomegaly from cardiac atrophy, impaired myocardial blood flow and loss of arterioles resulting in severe systolic dysfunction (5). These cardiogenic effects of hypothyroid state leading to depressed ionotropy and chronotropy with compensatory vasoconstriction are believed to be a result of low 
intracellular T3. The hypothyroid heart attempts to perform by better coupling of ATP to contractile events until a precipitating event disrupts this fine balance (6). This resultant de-compensation leads to hypotension and cardiogenic shock that may not respond to vasopressors alone until thyroid hormone replacement is given.

Treatment usually involves intensive care admission with cardiopulmonary support, aggressive fluid and electrolyte management, treatment of underlying and precipitating factors and thyroid hormone replacement. Intravenous T4 is the most commonly used preparation as intestinal absorption may not be reliable. In severe illness, the conversion of T4 to T3 by 5'-monodeiodinase is impaired. Intravenous T3 preparation should be used. Improved cardiac function is reported in 24 hours when T3 replacement is used and it may take up to a week to notice beneficial effects with T4 replacement alone (7).

\section{References}

1. Mathew V, Misgar RA, Ghosh S, Mukhopadhyay P, Roychowdhury P, Pandit K, Mukhopadhyay S, Chowdhury S. Myxedema Coma: a new look into an old crisis. J Thyroid Res. 2011:493462. [CrossRefl [PubMed]

2. Wartofsky L, Myxedema Coma, Endocrinol Metab Clin N Am. 2006; 35(4): 687-98. [CrossRef] [PubMed]

3. Brent GA, Davies TF. Hypothyroidism and thyroiditis. In: Melmed S, Polonsky KS, Reed P, Kronenberg HM, eds. Williams Textbook of Endocrinology. Philadelphia, PA: WB Saunders, 2008.

4. Schenck JB, Rizvi AA, Lin T. Severe primary hypothyroidism manifesting with torsades de pointes. Am J Med Sci. 2006 Mar; 331(3): 154-6. [CrossRef] [PubMed]

5. Tang YD, Kuzman JA, Said S, Anderson BE, Wang X, Gerdes AM. Low thyroid function leads to cardiac atrophy with chamber dilatation, impaired myocardial blood flow, loss of arterioles, and severe systolic dysfunction. Circulation. 2005;112(20):3122-30. [CrossRef] [PubMed]

6. W. M. Wiersinga. Hypothyroidism and myxedema coma. In: Jameson JL, Legroot LJ, eds. Endocrinology: Adult and Pediatric. Philadelphia, PA: Saunders Elseiever, 6th edition, 2010:1607-22.

7. Mackerrow SD, Osborn LA, Levy H, Eaton RP, Economou P. Myxedema associated cardiogenic shock treated with intravenous triiodothyronine. Ann Int Med. 1992;117:1014-5. [CrossRef] [PubMed] 